\title{
EL SALARIO MÍNIMO MINIMIZADO COMO CASO DE HEGEMONÍA NEOLIBERAL
}

Mauro Basaure ${ }^{1}$

\section{Resumen/Abstract}

La noción general de salario mínimo, que es una figura legal que regula el mercado de trabajo, esconde en sí una diferencia radical. De ser expresión de un compromiso entre capital y trabajo en el marco de un proceso de negociación colectiva, pasa a ser, en el contexto de la hegemonía neoliberal, una imposición, un pronunciamiento tecno-económico y administrativo. Con la ayuda de la teórica política Chantal Mouffe, en este artículo examino tres mecanismos que permiten vislumbrar, de modo concreto, cómo se expresa, justifica y afirma la hegemonía neoliberal en el terreno particular, pero muy sensible, del salario mínimo. Esos mecanismos generan la exclusión de aquello que políticamente sea fuente de antagonismo o siquiera controversia, y las formas de validar y reproducir esa exclusión, sea cognitiva o moralmente. ${ }^{2}$. dominación

Palabras claves: Salario mínimo, hegemonía neoliberal, antagonismo, bien común, MINIMUM MINIMIZED WAGE AS A CASE OF NEOLIBERAL HEGEMONY

The general notion of minimum wage, which is a legal instrument that regulates the labor market, hides a radical difference. First expressing a compromise between capital and labor within the framework of a collective bargaining process, it then, in the context of the neoliberal hegemony, turns into a techno-economic and administrative imposition, a pronouncement. In this article, with the help of the political theorist Chantal Mouffe, I examine three mechanisms which allow to comprehend, in concrete terms, how neoliberal hegemony expresses, justifies and affirms itself in the particular and essential field of minimum wage. These mechanisms generate the exclusion of what, politically, is a source of antagonism or even controversy, and bring forth ways to validate and reproduce such an exclusion, either cognitively or morally. domination

Keywords: Minimum wage, neoliberal hegemony, antagonism, common good,

\footnotetext{
${ }^{1}$ Chileno. Universidad Andrés Bello y del Centro de Estudios de Conflicto y Cohesión Social, COES. EMail:mauro.basaure@gmail.com

2 Proyectos de Investigación: Fondecyt 1140344; Fondecyt 1150790; Conicyt/Fondap/15130009.
} 


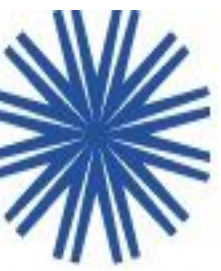

Introducción

El salario mínimo es una regulación al mercado de trabajo. Si en el contexto del Estado de Bienestar una tal regulación es propia a la fórmula socialdemócrata de establecer la relación entre Estado, capitalismo y trabajo, resulta una especie de anomalía el que tal regulación persista en el marco de la liberalización extrema del mercado - especialmente el mercado de trabajocomo la que tiene lugar en el contexto de la hegemonía neoliberal. En este contexto, parece ser tolerado por razones funcionales, como lo había visto Marx. Pues, qué otra razón puede haber para regular un mercado en medio de una ideología del libre mercado que, además, en algunos casos, ha destruido a las organizaciones obreras mediante golpes y dictaduras, sino es saber que ese mercado necesita un mínimo de regulación para subsistir.

Localmente, la racionalidad que gobierna el salario mínimo en el neoliberalismo es la de la minimización de un costo necesario, de un costo de capital fijo, y la legislación neoliberal apoya esa racionalidad paramétrica del empresario. De otro lado, asumiendo la necesidad del salario mínimo como una auto-limitación funcional del capitalismo (Boltanski/Chiapello 1999), globalmente, el principio de racionalidad minimizadora reside en la minimización de sus supuestos efectos perversos. El salario mínimo afectaría la flexibilidad del mercado de trabajo, pues lo tornaría rígido; encarecería la contratación de mano de obra poco calificada; aumentaría la tasa de desempleo, especialmente entre los jóvenes; aumentaría la contratación informal pues ésta sería la alternativa frente a las restricciones que imponen el salario mínimo y las prestaciones sociales, con lo que aumentaría el nivel de incumplimiento de la normativa legal por parte de los empleadores. De este modo, la minimización de tales efectos está en función de la minimización del salario mínimo.

Según lo dicho, la noción general de salario mínimo esconde en sí una diferencia radical. Se trata de aquella marcada por el siguiente desplazamiento: De ser, en el contexto socialdemócrata, expresión y resultado, asegurado jurídicamente, de un compromiso entre capital y trabajo en el marco de un proceso de negociación colectiva también regulado, pasa a ser, en el contexto de la hegemonía neoliberal, una imposición, un anuncio tecno- 
económico y administrativo. $\mathrm{Si}$ en el primer escenario el salario mínimo expresaba explícitamente una diferencia de intereses entre capital y trabajo, en el segundo, se la busca borrar mediante una referencia objetiva a la dinámica necesaria del mundo de las cosas, en la que ambas partes debiesen necesariamente coincidir. Esa diferencia de interés sigue existiendo, sin duda, pero a ella se le impone una referencia externa, un tercero término igualador, supuestamente unitario y superior, que genera equivalencia entre las partes, de orden objetivo y neutral, pero que no es de orden jurídico sino relativo al orden del mundo. Mediante esta referencia equivalencial objetiva, se pasa de un régimen de disputas juridificadas a uno de pacificación obligada, vía la imposición de dicha referencia a la objetividad del mundo; esto dicho según los términos de Luc Boltanski (1990) en su teoría de los regímenes de acción. Efectivamente, cuando se trata de la política neoliberal de fijación del salario mínimo, todo se da dentro de un paradigma único y que de hecho se deja simplificar — sin pérdida de contenidos — en términos de una referencia a efectos perversos sobre el índice de desempleo, que se dan por necesarios, conocidos y cuantificables.

Según lo dicho, se puede hablar de una indexo-política; de una política hecha vía referencia a índices, que expresarían estados de la realidad, con el objetivo de tomar decisiones claves, sobre todo en el ámbito de la reproducción material de la sociedad. En este ámbito, estos indicadores cubren de hecho todo el espectro temporal: el pasado (lagging indicators), el presente (coincident indicators) y el futuro (leading indicators), y se los usa como brújulas para guiar la práctica. Esta indexo-política se ha mostrado extremadamente robusta en el contexto de sociedades que han sido objeto de las reformas estructurales de orden neoliberal.

Aun cuando en muchas de esas sociedades tales reformas han sido impuestas por la fuerza, eliminando o debilitando al máximo tanto la legislación que protegía a los trabajadores como a sus propias organizaciones, la fuerza de la ley o la represión política no permiten comprender la robustez y permanencia de las políticas neoliberales del salario mínimo en las últimas décadas. El origen violento y hasta revolucionario del neoliberalismo (Duménil/Lévy 2004; Hall 2011; Brown 2015) no explica su permanencia. Aunque sea cierto que, en las últimas décadas, estamos en presencia de una hegemonía casi no desafiada del neoliberalismo, no resulta muy instructivo decir que ello es la razón de la robustez y permanencia de la política minimalista del salario mínimo. 
Teorías de la hegemonía, como la propuesta por Mouffe y Laclau (1985), invitan a preguntarse por aquellos mecanismos, de orden estrictamente político, que le permiten a un orden, cualquiera sea, constituirse como un orden capaz de reclamar un carácter necesario, legítimo y de anular la visión sobre la configuración particular de relaciones de poder sobre la que se asienta. La apelación a lo universal, la instauración de un sentido común, la exclusión de alternativas, entre otros son prácticas constitutivas claves de la hegemonía.

Asumiendo lo anterior la pregunta es cómo, bajo qué mecanismos, la hegemonía neoliberal se da lugar en el caso preciso de la cuestión del salario mínimo. En este artículo reviso la siguiente posible respuesta general a tal pregunta: lo que ayuda a comprender mejor la robustez y persistencia de un salario mínimo extremadamente minimizado — como es el que se da constantemente en contextos neoliberales - es la presencia de mecanismos que ocultan precisamente el hecho de que tal salario mínimo expresa una determinada correlación de fuerzas entre intereses dispares, expresados bajo los conceptos generales de capital y trabajo. Esto, que era la base de la idea de compromiso y negociación en el contexto socialdemócrata, es ocultado en el contexto neoliberal mediante el recurso y la apelación a cuestiones de orden universal y formas de justificación moral. Se trata de la apelación a la realidad externa y sus cambios, a la neutralidad de los índices que interpretan esa realidad y esos cambios, y a la preocupación por el bien común y por el bienestar de los más pobres. En particular reviso aquí: la exclusión de aquello que políticamente sea fuente de antagonismo o siquiera controversia $[\mathrm{I}]$ y las formas de validar y reproducir esa exclusión, ya sea cognitiva [II] o moralmente [III].

\section{Excluir, anular y separar el antagonismo y sus fuentes}

El mencionado desplazamiento implica varias formas y niveles de exclusión del antagonismo y de aquello que sea la fuente del antagonismo o siquiera de controversia. Todas esas formas son concomitantes. Se trata de la exclusión, por principio, de cualquier alternativa [1], de la "expertización" de la política [2], y de la comprensión y práctica de la política reducida a los límites de un sistema separado de la ciudadanía [3]. 


\section{La no alternativa a los indices}

La indexo-política excluye, por principio, la referencia a paradigmas alternativos. Esto es una dimensión clave de la comprensión de un orden hegemónico, tal como lo han estudiado Chantal Mouffe y Ernesto Laclau (1985). Mouffe (2005) lo ve ejemplificado en la así llamada gobernanza gobal (global governance). Esa política pública, por principio, no cuestiona el marco o la construcción hegemónica al interior del que ella opera. Lo hace dentro de un escenario no tematizado políticamente. No cabe en ella, por tanto, la posibilidad de tener opciones distintas a ese marco; su tarea es tener negociaciones técnicas al interior de él de cara a "resolver problemas". En coincidencia con los análisis de Mouffe, Slavoj Žižek (2006) parte de la tesis de que las elites presentan permanentemente una elección que no es una elección, de modo que los ciudadanos son llevados a ratificar decisiones ya tomadas. De hecho, agrega que toda discusión sobre estas decisiones es una interrupción, un ruido molesto para esta post-política; un ruido de ignorancia e ideología, de las viejas pasiones de izquierda o derecha.

De modo equivalente, el tratamiento anual de la fijación del salario mínimo no tematiza siquiera, por ejemplo, el que tal fijación se realice en base a un concepto justo de salario mínimo, de un monto mínimo vital o digno. Se omite la cuestión de la relación porcentual entre los salarios más bajos y los salarios más altos; que tematizaría a su vez la amplitud de la brecha de la desigualdad en función de los grados de integración social que una comunidad política quiere darse a sí misma. En vez de existir planteamientos en torno a una cuestión que requiere una decisión política (aproximarse, por ejemplo, a la brecha de salarios reinantes en los países de la OCDE), basada en principios éticos y de justicia. En vez de todo ello, el debate sobre el salario mínimo es forzado a plantearse en el estricto marco de la relación con el índice de desempleo. El problema no es que no exista debate. Este tiene lugar año a año, pero él opera dentro de una cierta hegemonía que ha fijado de antemano los límites de lo posible, de lo debatible con sentido. Todo lo anterior es desatendido ahí donde la única pregunta permitida es hasta qué punto se puede aumentar el salario mínimo sin que aparezca el efecto perverso - considerado necesario, conocible y cuantificable - de un aumento supuestamente concomitante en los índices de desempleo y, con ello, en los de la pobreza, además de otros posibles efectos negativos sobre la economía nacional. 


\section{La expertización de la política}

En directa relación con lo anterior, se excluye la validez de cualquier visión antagonista o siquiera la posibilidad de la controversia, en la medida que se considera que sólo hay una decisión correcta y esta emana de cálculos expertos. El hecho de que la fijación del salario mínimo tenga por única referencia el índice de desempleo significa que ni siquiera al interior del propio modelo hegemónico cabe discutir políticamente dicha fijación pues ella es una cuestión que debe ser dejada exclusivamente a expertos. En principio se excluye hasta las controversias entre expertos.

Lo anterior, obviamente, deslegitima conceptual y excluye prácticamente, por ejemplo, aquella tradición que busca fijar el salario mínimo en base a una mesa tripartita (gobierno, empresarios, trabajadores), pues de qué podría valer la voz de quienes (todos ellos) no cuentan con el saber técnico. Ahí donde habla la técnica, no puede haber discusión pues es irracional discutir sobre las verdades tecno-científicas que hablan sobre los límites posibles de la realidad. Desde Hannah Arendt (1958), Jürgen Habermas (1968) hasta Luc Boltanski (2009, 2012) esto se ha identificado como una de las patologías de las sociedades modernas: ahí donde los ciudadanos debían discutir sobre las reglas que querían darse a sí mismos para configurar su realidad, ahí una política acaparada en la ciencia y la técnica.

Por vía de la analogía Mouffe $(2000,2005)$ extiende esta crítica a parte importante del pensamiento político contemporáneo, desde el liberalismo hasta la nueva izquierda. Según Mouffe (2000), el liberalismo — esto es básicamente en su vertiente racionalista de John Rawls (1997, 2001, 2005) y Habermas (1992) — niega el carácter inerradicable del antagonismo, pretendiendo subsumirlo bajo una solución racional supuestamente capacitada para generar armonía y cohesión social. Los esfuerzos de este liberalismo se enfocan en superar el antagonismo y no en comprender su relevancia para el propio significado de la democracia. El comunitarismo, por su parte, que apela a una noción única y sustantiva del bien, como base de la cohesión social, incurriría en el mismo déficit en el sentido de dar por superada ex ante la pluralidad y el carácter controversial de formas de bien común. 
Los anteriores son ejemplos de lo que Mouffe entiende como equivalentes a la centralidad e influencia de voces expertas en la vida política. En todos estos casos se clausuraría el espacio para la política, sea, de una parte, mediante la idea de un consenso racional o una coincidencia sustantiva de valores, sea, de la otra, por la imposición de una verdad científico-técnica; o por la configuración normativa de ambas, es decir, por el consenso exigido en torno a un juicio experto ${ }^{3}$. Mouffe (2005) también reconoce críticamente este aspecto en la gobernanza global. El problema no es el tipo de motivación ética de las asociaciones y organismos de la global governance, ocupadas sin duda de cuestiones reales y urgentes que afectan a las personas. El problema es que estas son tratadas como población afectada por cuestiones de orden medioambiental, migratorio, etc., y son clasificadas, identificadas y tratadas por profesionales con experticias específicas. Contra esta perspectiva, Mouffe refiere al diagnóstico de Ulrich Beck $(1986,1991)$ sobre el reciente cuestionamiento del carácter irrebatible de la voz de los expertos; fenómeno que para Mouffe cambia el significado mismo de la política.

\section{La separación de un ámbito político especializado}

En directa relación con lo anterior, el antagonismo y sus posibles fuentes son también excluidos en la medida que las cuestiones políticas son concebidas como una esfera autónoma de decisión. Según la descripción crítica de Laclau y Mouffe (1985), el que nuestras sociedades estén relativamente imposibilitadas de abordar políticamente sus cuestiones fundamentales es consecuencia no sólo de la ficción de su posible resolución racional y neutral sino también, de modo concomitante, de la idea de que la tarea de tal resolución debe ser funcionalmente diferenciada en un ámbito específico y autonomizado de acción técnico-administrativa; en todo caso, no sólo ajeno sino que además indiferente y despreciativo de las prácticas democráticas de los ciudadanos.

3 Es el caso de Rawls cuando frente a cuestiones controversiales deposita la confianza en las conclusiones de las ciencias empíricas como tribunal que permita dirimir racionalmente las controversias (Rawls 1993). Para ver los límites de esta perspectiva en el caso específico de la controversia en torno al reconocimiento jurídico del matrimonio entre personas del mismo sexo ver: Basaure 2015. 
En su crítica a la tecnificación de la política, Mouffe coincide con el diagnóstico del Habermas (1968) de Ciencia y Técnica como Ideología, aunque su postura final será muy distinta y contraria a la de este autor. Ambos son críticos de Luhmann. La tesis liberal de la neutralidad del Estado y la teoría luhmanniana del sistema político como funcionalmente diferenciado, a sus ojos, coinciden: El liberalismo de la neutralidad del Estado defendido, por ejemplo, por Charles Larmore, dice Mouffe, "refuerza una tendencia, ya demasiado presente en el liberalismo, a transformar problemas políticos en cuestiones administrativas y técnicas, y ello consuena con teorías neoconservadoras como la de Niklas Luhmann, quien pretende restringir el ámbito de las decisiones democráticas poniendo cada vez más áreas bajo el control de expertos supuestamente neutrales" (Mouffe 1993: 48) ${ }^{4}$.

Con lo anterior, Mouffe daba continuidad a cuestiones ya avanzadas en Hegemonía y Estrategia Socialista (Laclau/Mouffe 1985). De manera muy adecuada a los tiempos, en ese libro, Laclau y Mouffe acusaban la arremetida de la derecha neoconservadora contra el Estado socialdemócrata, al que entendían como una configuración históricamente específica del vínculo entre liberalismo y democracia producto de las luchas sociales del siglo XX. En su análisis entendían que este ataque implicaba una redefinición de la democracia de tal modo que ésta quedaba reducida en su campo de aplicación y la participación política era arrinconada en un lugar cada vez más estrecho. La fórmula para ello habría sido la separación del sistema político $-\mathrm{y}$ su concepción como un sistema autónomo - respecto de la sociedad. Con ello, el sistema político quedaba a cargo de las decisiones públicas de la sociedad, pero sin el control político ciudadano. La democracia no es atacada directamente, dice Laclau y Mouffe, pero sí vaciada de su sustancia y de hecho usada ella misma (ya redefinida) para legitimar "un régimen en el que la participación política podría ser virtualmente inexistente" (Laclau/Mouffe 1985: 173). Este nuevo concepto de democracia (neo)libertaria se conforma con asegurarle a los individuos ciertas áreas de autonomía para su auto-expresión individual y el desarrollo de formas de vida particulares, asegura su participación como consumidores, excluyéndolos, sin embargo, de los procesos de decisión sobre cuestiones políticas fundamentales de la sociedad, es decir, en tanto que ciudadanos. No es por

4 La traducción es nuestra. 
tanto casualidad que finalmente, en el contexto neoliberal, sean básicamente los gobiernos, mediante el Ministerio de Hacienda, el que termine imponiendo su visión tecnocrática experta frente a demandas ciudadanas.

Estos tres procesos, descritos arriba, van de la mano en el caso del salario mínimo neoliberal. Su diferenciación es necesaria, sin embargo, pues no se coinciden necesariamente. La "expertización" de la política, por ejemplo, ha sido puesta en cuestión y tratada mediante programas de participación ciudadana, mesas técnico-sociales, etc.; todo ello sin tocar la construcción hegemónica al interior del que operan esos programas, ni la lógica de una política como ámbito separado. Asimismo, programas anti-hegemónicos puede también, en principio, basarse en una lógica de expertos, etc. Por otro lado, dichos procesos, por cierto, no son propios a la cuestión del salario mínimo neoliberal. Lo que se puede decir de ellos es que, con dicha cuestión, por su propia lógica económico-política, esos procesos son exigidos, haciendo que ellos se expresen de manera muy evidente, sistemática; configurando un dispositivo coherente.

\section{La validación y reproducción cognitiva de la exclusión del antagonismo y sus fuentes}

La exclusión del antagonismo, o de la posibilidad de este, está además apoyada por dos formas de validar y reproducir esa exclusión, basadas específicamente en el uso de los indicadores. La primera, opera mediante la generación de impotencia en el ciudadano [1] y la segunda, en un sentido equivalente, por la vía de la manipulación del cambio [2].

\section{Generación de impotencia mediante el uso de indicadores}

La indexo-política genera un efecto de aprendizaje negativo en el sentido de que inculca en el ciudadano el no ser y no poder ser en absoluto competente en cuestiones políticas. Los indicadores registran fuerzas ocultas, de agregados no intencionales de la acción, que cognitivamente se le escapan irremediablemente al ciudadano. Sheldon Wolin (1992) conduce y traduce todo esto en términos de una interesante teoría de la dominación. Según él, la economía política ha transformado la idea liberal clásica del ciudadano como detentador de derechos 
políticos y sociales individuales en una figura cuya existencia se expresa en indicadores que informan cuál es su "real" condición objetiva; esto es, aquella condición real que él no puede percibir pero que es más real y objetiva que lo que alcanzan a ver sus sentidos y que se encuentra sintetizada en indicadores de desempleo, inflación, precios, gastos, pobreza, etc. En un sentido equivalente a cómo las políticas sociales ponen a pobres, inmigrantes, etc. en una situación de pasividad, los índices ponen al individuo de la indexo-política en una posición pasiva y asimétrica pues un "índice... no le dice al individuo lo que está haciendo, sino que le está ocurriendo" (Wolin, 1992: 248) y esto según el registro de fuerzas sociales que tienen lugar más allá de su habilidad para influenciarlas y controlarlas.

Lo clave para Wolin es que estos indicadores, que son muy útiles a quienes tienen el poder de tomar decisiones, constituyen simultáneamente un símbolo de impotencia y, por lo mismo, una fuerza con mucho poder persuasivo para generar despolitización entre quienes no tienen ese poder. Si dicha despolitización es deseable y ésta se genera mediante la impotencia entonces es deseable recurrir a lo que la produce, es decir, a la política mediante índices o indexo-política. Cada vez que se la usa se está dando una lección de impotencia a los individuos y, con ello, se contribuye a su pasividad. El argumento de Wolin hace aparecer el carácter político del uso de índices. Lo que aparece como neutralidad y mera indicación de los estados reales de la realidad adquiere ahora un carácter político. Muestra, de modo inesperado, el carácter político de lo que se impone como apolítico: La indexo-política que se presenta como no política, es política no sólo en sentido de que puede develarse su carácter hegemónico, sino que también por los efectos de sumisión despolitizadora e infantilización que genera en la ciudadanía; efectos que están, muchas veces de modo consciente, a disposición de un proyecto conservador. La indexo-política se presenta como un marco no negociable que, sin embargo, se pone a disposición como objeto de lección. Una noelección que debe aleccionar. Žižek (2006) tiene razón cuando señala que, cuando se eleva la discusión y aparecen ruidos por parte del pueblo, la auto-crítica típica que asumen las élites es no haber sabido comunicarse bien con el pueblo, puesto que si lo lograsen éste no podría sino dejar de lado su inmadurez. Daniel Contreras, socio gerente general de la empresa Falcon, que otorga servicio de management a empresas públicas y privadas, señala con meridana claridad: "Es por eso que a esta negociación [la del salario mínimo en el congreso, MB] le hace falta un cambio de táctica. ¿Qué pasaría si el ministro de Hacienda o el de Economía en cadena nacional repasaran 
brevemente el racional que existe detrás de este argumento? ¿No sería eso mejor que escuchar a diputados de todos los ángulos "opinar" sobre lo que ellos "creen” que sucedería? La relación entre desempleo y salario mínimo no es tan intuitiva, sin embargo, no es materia de opinión: mayor salario mínimo genera más desempleo, punto. [...] Es importante que en este punto las autoridades ya se detengan a analizar: ¿Invierto mi tiempo y fuerzas en "alinear" y negociar con una decena de diputados o en compartir conocimiento con la población? Insistimos, al oficialismo, a la oposición y los grandes empresarios se les olvida un acto ¡la población!” (Contreras, 2012).

\section{La manipulación del cambio}

La exclusión del antagonismo y de sus posibles fuentes se apoya en el modo en que se interpreta el cambio social que afecta la economía nacional. Efectivamente, la ya problemática ecuación entre la fijación del salario mínimo y el índice de desempleo es además puesta a disposición de una interpretación —a la que también se autoriza sólo a expertos— sobre el estado de la economía nacional en relación a la fluctuación, el cambio y las crisis actuales o potenciales de la economía mundial, y sus posibles consecuencias. Con ello, con esta zona gris de interpretación, se abre un nuevo espacio de reproducción y justificación de las decisiones, y con ello de exclusión de visiones antagonistas.

Boltanski habla de dominación por el cambio: "El cambio en cuestión no es tanto un cambio presente como un cambio anunciado. No se le conoce aún, o bien solo incompletamente. Es necesario, entonces, invocar a los expertos en ciencias sociales y a centros de cálculos y de previsión para concebir este cambio que más tarde se les impondrá inevitablemente a todos. En un marco formalmente orientado hacia el bien común [...], la insistencia en la necesidad es fundamental para legitimar la acción política. En efecto, en un marco tal, una acción es ilegítima cuando se la puede llamar arbitraria, al demostrar que está sometida a la voluntad de un individuo o de un grupo que asumiría por sí mismo las decisiones. Invocar fuerzas impersonales e inexorables permite subordinar la voluntad de los actores en posición dominante a las leyes inscritas en la naturaleza de las cosas" (Boltanski, 2012: 78). Apoyada en esta interpretación del cambio por venir, la indexo-política aparece como reacción necesaria. El conflicto interno entre capital y 
trabajo, queda pacificado mediante la defensa de la nación frente amenazas venidas desde exterior. Francois Dubet y Danilo Martuccelli lo escriben del siguiente modo: “... la representación de la sociedad en términos de conflicto y de relaciones sociales es sustituida por una que enfrenta el modelo nacional a los mercados financieros, la mundialización, las fuerzas destructivas venidas desde el exterior. Ya no son las clases que se confrontan, sino que es la nación que se defiende contra los cambios impuestos desde el extranjero y retransmitidos por élites que pretenden dominar estas mutaciones "inevitables"'” (Dubet/Martuccelli 1998: 126).

Con ello se entrega a expertos economistas la mayor de las arbitrariedades para definir el estado de la realidad y el mayor de los poderes, pues aparecen como los generales defensores de la nación frente a riesgos y crisis que amenazan desde el exterior. En base a esto pueden justificar medidas de todo tipo; en este caso la minimización del salario mínimo. Cabe agregar que el carácter de dicha interpretación — es decir, como positiva o negativa — no determina la decisión: en un plano promisorio resultaría aconsejable no modificar ninguna variable de la economía; en un plano de crisis menos aún. El diputado chileno Jorge Tarud (2013) lo expresó bien diciendo que el ministro de Hacienda, bajo el gobierno derechista de Piñera, Felipe Larraín, "cuando va a Davos o cuando va a Washington habla maravillas de la economía chilena, pero cuando regresa a Chile es quien lidera la campaña del terror para la inversión”. En fin, pese al constante cambio, lo único constante es la presión minimizadora sobre el salario mínimo, pues en el marco de la indexopolítica no hay espacio para una presión en la dirección contraria. Eso es tal vez lo único que no puede justificar la indexo política neoliberal, a saber: por qué su presión es siempre minimizadora, por qué nunca adopta la dirección contraria; por qué siempre termina coincidiendo con los intereses del capital.

\section{La validación y reproducción moral de la exclusión del antagonismo y sus fuentes}

Lo dicho más arriba sobre los mecanismos de exclusión del antagonismo y de su invalidación cognitiva es acompañado además por de un discurso de justificación moral, relativo al bien común. Efectivamente, sería un error derivar de lo dicho arriba que la indexo-política se 
desentiende de un discurso moral. Lo cierto es que éste resulta del apego estricto a la técnica económica neoliberal. Es, de hecho, precisamente este apego lo que permite desarrollar una ética del bien común e incluso de una suerte de teología de la "opción preferencial por los pobres". Tres son los elementos implicados en esta opción ética: una autolimitación de supuestos ideales de justicia [1]; una cruzada contra quienes pretendan transgredir el discurso experto [2] y; un programa social compensatorio [3].

\section{La autolimitación de los propios ideales de justicia social}

El supuesto detrás del modo en que se plantea el discurso hegemónico neoliberal sobre el salario mínimo es que, en realidad, el paso del continuum político (según el que, en su forma legal, dicho salario estabiliza un compromiso entre capital y trabajo) a una indexo-política, es algo que se impone a todos los actores. Si tal indexo política coincide con el interés minimizador del salario mínimo que tienen capitalistas, eso es contingente y no expresaría en absoluto que tal indexo política esté en favor del capital. En la tecno-ciencia no habría interés. En principio, todos quieren subir el salario mínimo (nadie quiere defender los intereses mezquinos), pero —en interés de toda la sociedad y sobre todo de los más pobres—-, se debe actuar responsablemente. El mensaje es que para ayudar a los más pobres no hay que buscar un salario mínimo justo y digno sino sólo aquél que economistas decretan y definen como "correcto"; es decir, adecuado a la estabilidad macroeconómica del país, sobre todo, como se ha dicho, en el contexto de las fluctuaciones internacionales.

Por otra parte, esta referencia técnico-económica a índices determina una autolimitación de lo que se afirma es una intención moral, en principio, coincidente con el interés de los trabajadores en aumentar el sueldo mínimo lo máximo posible. Pero la indexo-política tiene la convicción de que el mayor bienestar se alcanza sin justicia. Cuando opera un régimen de la supuesta objetividad de la realidad de las cosas, no hay disputa por la justicia (Boltanski 1990). Al interés por la justicia, compartido por unos y otros, debe oponérsele la realidad de cómo interactúan los indicadores económicos: Todos quisieran un salario mínimo justo, pero lo único responsable es aspirar al salario mínimo técnicamente correcto. La división de la sociedad, ya no es más dependiente de intereses ni políticos ni morales, sino que de cómo uno se posiciona frente a la 
realidad de las cosas; si sometiéndose a ella (acusando incluso cierto padecimiento) o con una actitud prometeica irresponsable. Una política como la descrita exige renunciar pragmáticamente, por tanto, a los propios ideales de justicia. Exige una auto-limitación racional. Lo posible reemplaza lo deseable y a aquello considerado justo y solidario. La economía, como lo ha planteado Jean Baudrillard (1998), opera como "principio de realidad”, en sentido psicoanalítico.

2. La ética de la responsabilidad contra la ética de la convicción

El salario mínimo minimal del neoliberalismo supone una comunidad de interés nacional, que se asocia con el lugar objetivo, neutral y racional, expresado en un balance entre variables. Plantear las cosas en términos de interés (de modo político) sería signo de estupidez, como la que sufren quienes siguen presos de ideologías no sólo de izquierda, sino también de derecha. Conceptualmente, la indexo política neoliberal no es, técnicamente hablando, política de derecha; es decir, siéndolo, logra transmutarse en su auto-negación.

En principio, el argumento no es de contigencia, sino de necesidad, pues tales efectos se declaran completamente conocidos y anticipables. En estos términos Max Weber (1988) opuso la ética responsabilidad (Verantwortungsethik) a la ética de la convicción o de fines últimos (Gesinnungsethik); distinción que ha sido usado reflexivamente para denostar fundamentalmente a quienes entienden la política en términos del esfuerzo por realizar ideales de justicia. En su texto "La objetividad del conocimiento en las ciencias y en la política sociales", Weber dice: "Puedes demostrarle a un sindicalista convencido; seguidor de una ética de fines últimos, que su acción tendrá como consecuencia [...] obstruir su progreso [...]. No le causarás la más ligera impresión. Si una acción bien intencionada tiene malas consecuencias, entonces, desde el punto de vista del actor, el responsable del mal no es él, sino el mundo, la estupidez de los demás, la voluntad divina que hizo las cosas así" (según Giddens 1994: 230). La ética de la responsabilidad exige conformarse, nos guste o no, con el salario mínimo correcto. La ética de la convicción

5 La traducción es del autor 
—irresponsable, por muy bien intencionada que sea- exige un salario mínimo justo (léase aquí, por sobre el límite de lo correcto) y con ello genera un mal social.

En base a este convencimiento y a la auto-renuncia de los propios ideales de justicia, la indexo-política neoliberal obliga a combatir a quienes, no asumiendo el principio de realidad, politizan o ideologizarían el debate sobre el salario mínimo. Se trata de una obligación que apela al resguardo del bien común. Este es su aspecto más activo. Pese a compartir intenciones e ideales de justicia social con sus opositores, la indexo-política debe combatirlos. El problema no es de principios morales sino de cómo se relaciona con ellos: mientras que unos lo harían de manera responsable los otros, al orientarse por fines últimos y dejar de lado la consideración de los efectos perversos, serían irresponsables.

\section{Preocupación y compasión con los pobres}

Los ideales de justicia auto-limitados por el sometimiento al principio de realidad y su consecuente afirmación de una ética de la responsabilidad encuentran un substituto y apaciguamiento en la convicción de hacer lo mejor posible por los trabajadores más pobres, de una parte, y en una suerte de compasión por ello, de la otra.

Mientras que, en el marco del modelo político del continuum, el salario mínimo se alcanzaba en la forma de un compromiso después de una negociación; ahora se lo alcanza como el máximo esfuerzo que pueden indicar los expertos responsables. No se niega, de hecho, que el salario mínimo minimal que se propone sea paupérrimo, que no permita una vida digna. Se sabe que no es justo, pero se lo asume como ajustado a la realidad posible. Se celebra, sin embargo, el reajuste, por mínimo que sea. Incluso si el reajuste anual es de 1 o 2 dólares, eso debe ser considerado como el máximo esfuerzo posible y, por tanto, como la verdadera preocupación por los trabajadores más pobres. Ejemplo de ello son las palabras del diputado Ernesto Silva (2013), del partido de derecha chileno, Unión Demócrata Independiente (UDI), cuando señala que "la oposición [al gobierno derechista de Piñera] no tiene compasión con los trabajadores; sin ningún argumento, sin ninguna razón y quizás por la instrucción de quién, ha decidido oponerse al reajuste más importante que se ha planteado...”. Frente al congreso el gobierno de Sebastián Piñera, en la 
voz de su ministro de Hacienda, Felipe Larraín, se presentó a sí mismo como haciendo un enorme esfuerzo "para que los trabajadores que ganan menos tengan su reajuste"; un objetivo puesto en peligro por quienes, irresponsablemente, pretenden "dejar sin reajuste a los trabajadores que tienen menos" (Larraín 2011).

Por todo ello, junto a su propia auto-limitación y a la cruzada contra el "principismo", al mismo tiempo se aboga por transferencias directas de ingreso a los sectores más pobres; de bonos, asistencias a las familias, y otras ayudas del Estado a los más pobres. Esta transformación de la política social, desde la idea de ciudadanos de derechos a la de receptor de ayuda social, tampoco aparece como una cuestión ideológica. Lo hace más bien como una consecuencia necesaria de una mirada responsable, no populista y desideologizada sobre el juego de variables económicas que tejen la trama de la realidad: Cómo no es posible realizar un salario mínimo digno, aparecen formas alternativas como, por ejemplo, un salario ético familiar que establece la entrega de bonos y transferencias condicionadas a ciertos rendimientos por parte del beneficiario. La indexo-política acompaña de este modo paliativo a los sectores populares.

\section{Conclusiones}

En los círculos académicos no es extraño evidenciar hoy en día un cierto hartazgo con el uso del concepto neoliberalismo. Ello debido a su uso indiscriminado y sin referencia empírica para resumir los males de la sociedad actual. Ese hartazgo es, en gran medida, justificado. Ello hace aconsejable dar cuenta de los modos concretos en que la hegemonía neoliberal se expresa, justifica y afirma en terrenos altamente sensibles, como, por ejemplo, el del salario mínimo. En

\footnotetext{
6 Este fue el concepto con que, en el marco de la transición chilena a la democracia, la nueva izquierda o socialismo renovado trató a su propio pasado y a quienes no aceptaban la renovación y seguían predicando el conflicto de clase, etc. La citada dicotomía weberiana (Weber 1988) entre ética de la responsabilidad y ética de la convicción, fue también muy útil. Principista cuya práctica política es conducida por la ética de la convicción. Esta jerga fue parte de la estrategia con la que se excluyó las demandas de justicia y democracia con las que el pueblo chileno se había movilizado contra la dictadura. La consigna fue y es "en la medida de lo posible". Si antaño debía respetarse la fragilidad de la democracia, hoy debe respetarse la fragilidad de la economía. En ambos casos hay expertos que saben bien sobre tales fragilidades. Nuevamente, todo ocurre como se no se tratase de diferencias de intereses, sino sólo de dónde ubicar los límites.
} 
este artículo he seguido la invitación de autores como Laclau y Mouffe a preguntarse por aquellos mecanismos, de orden estrictamente político, que le permiten a un orden, cualquiera sea, constituirse como un orden capaz de reclamar un carácter necesario, legítimo y de anular la visión sobre la configuración particular de relaciones de poder sobre la que se asienta. La apelación a lo universal, la instauración de un sentido común, la exclusión de alternativas, entre otros son prácticas constitutivas claves de la hegemonía.

Siguiendo esta invitación en este artículo he examinado tres mecanismos que permiten vislumbrar, de modo concreto, cómo se expresa, justifica y afirma la hegemonía neoliberal en dicho terreno. Esos mecanismos generan la exclusión de aquello que políticamente sea fuente de antagonismo o siquiera controversia, y las formas de validar y reproducir esa exclusión, sea cognitiva o moralmente. Estudiando la operación de estos mecanismos se hace evidente cuán difícil es posicionarse críticamente frente a la indexo-política y se entiende de modo concreto el significado de la hegemonía neoliberal.

Frente a ello la pregunta que se plantea Žižek es cómo puede ser concebido el "No" del pueblo; cómo resignificar aquello que es puesto como no alternativa, como una visión no consciente de sus propias consecuencias perversas, como mero miedo o instinto irreflexivo relativamente incapacitado para aprender y seguir la lección de los expertos. La cuestión es cómo la oposición a la indexo-política diga algo más que una mera negación, tenga para sí misma y los demás un significado que trascienda la reducción a ruido confuso y pasional en que se la ubica. El significado de ese "No", dice Žižek (2006) es la esperanza de que la propia política aún exista, de que el destino aún este abierto. En el contexto de estas notas, el "No" a la indexo-política significa o puede significar positivamente el esfuerzo por abrir el debate entre posiciones antagonistas en el marco de un rechazo a que exista una única elección que es la que confirma la elección ya hecha por el conocimiento experto en base a indicadores, pues todas las otras expresarían inmadurez irracional.

Para Žižek ese "No" ya expresa una experiencia de apertura frente a lo que se presenta como el cierre de un pensamiento único, como un fait-accompli político administrativo (Žižek 
2006), que no permita tomar decisiones políticas como ciudadanos sobre lo que se quiere que sea la sociedad. En este punto Žižek coincide con el concepto de política de Laclau y Mouffe y la crítica de ésta a todo escenario que niegue el antagonismo. El momento afirmativo del "No" a la indexo-política debe interpretarse, dice Žižek, como la elección por la propia elección ("the choice of the choice itself'). Significa que no hay nada sagrado, nada no transable, a excepción de la existencia de verdaderas alternativas en función de las cuales se pueda decidir, hacer política.

Efectivamente, la indexo-política es una política que niega la política; es una post-política, una forma de apropiarse de la idea de neutralidad que le permite acusar como política a quienes se le oponen; es una forma de desarmar a la crítica, quitándole el propio acceso a la realidad. Sin que hasta ahora seamos conscientes de ello, es precisamente esta capacidad de ciertos grupos de definir la realidad y sus límites lo que se pone cada vez más en el centro del debate. Una tarea clave de la política emancipatoria hoy resulta de su capacidad de disputar este terreno; esto es, recuperar para sí la propia capacidad de redefinir los límites de la realidad. El movimiento estudiantil chileno de los últimos años realizó esta novedad y precisamente por ello no responde estrictamente a las viejas ideologías comunistas, como varios han dicho. Ese movimiento puso en otro lugar los límites de lo real y, con ello, de lo posible. Ese movimiento vino a disputarle - a políticos y expertos- la capacidad de definir la realidad. De este modo los límites de la acción política responsable se transformaron. Se transformó así la definición de cómo ocuparse del bien común y del bienestar de la sociedad y de los más pobres. La gran disputa política de nuestro tiempo es una disputa por la realidad. La consigna de los movimientos sociales no es tanto "otro mundo es posible", como "otra realidad es posible".

\section{Referencias bibliográficas}

Arendt, Hannah (1958) The Human Condition, Chicago: University of Chicago Press.

Basaure, Mauro (2015) "Una gramática elemental de la controversia sobre el matrimonio entre personas del mismo sexo". En Liberalismo político. Problemas y desarrollos contemporáneos, Maximiliano Figueroa (ed.), Santiago: RIL Editores, págs. 161 - 178. 
Baudrillard, Jean (1988) Jean Baudrillard: Selected Writings, Mark Poster (ed.) Stanford, CA: Stanford University Press.

Beck, Ulrich (1986) Risikogesellschaft. Auf dem Weg in eine andere Moderne, Frankfurt am Main: Suhrkamp.

(1991) Politik in der Risikogesellschaft. Essays und Analysen, Frankfurt am Main: Suhrkamp.

Boltanski, Luc (1990) L'Amour et la Justice comme compétences. Trois essais de sociologie de l'action, Paris: Gallimard.

(2009) De la Critique. Précis de Sociologie de l'Émancipation, Paris:

Gallimard.

(2012) Sociología y Crítica Social, Mauro Basaure (ed.), Santiago: UDP.

Boltanski, Luc y Ève Chiapello (1999) Le nouvel esprit du capitalisme, Paris: Gallimard.

Brown, Wendy (2015) Undoing the Demos: Neoliberalism's Stealth Revolution, Cambridge, Massachusetts: MIT Press.

Contreras, Daniel (2012) “Opinión: salario mínimo, continúa la discusión entre dignidad y populismo", citado según: http://www.elmostrador.cl/mercados/destacadosmercado/2012/07/19/daniel-contreras-falcon/

Dubet, François y Danilo Martuccelli (1998) Dans Quelle Société Vivons-Nous? Éditions du Seuil: Paris.

Duménil, Gérard y Dominique Lévy (2004). Capital Resurgent: Roots of the Neoliberal Revolution, Cambridge, Massachusetts: Harvard University Press. 
Giddens, Anthony (1994) Capitalism and Modern Social Theory. An Analysis of the Writings of Marx, Durkheim and Max Weber, Cambridge: Cambridge University Press.

Habermas, Jürgen (1968) Technik und Wissenschaft als „Ideologie“, Frankfurt am Main: Suhrkamp.

(1992) Faktizität und Geltung. Beiträge zur Diskurstheorie des Rechts und des demokratischen Rechtsstaates, Frankfurt am Main: Suhrkamp.

Hall, Stuart (2011) “The Neo-liberal Revolution”, Cultural Studies, 25: 6, 705-728.

Laclau, Ernesto y Chantal Mouffe (1985) Hegemony and Socialist Strategy: Towards a Radical Democratic Politics, London/New York: Verso.

Larraín, Felipe (2011) Citado según: http://www.elmostrador.cl/ahora/2011/07/07/gobierno-ingreso-al-congreso-el-veto-presidencialpor-salario-minimo-con-reajuste-de-58/

Mouffe, Chantal (1993) The Return of the Political, London/New York: Verso. (2000) The Democratic Paradox, London/New York: Verso. (2005) On the Political, Abingdon/New York: Routledge.

Rawls, John (1997) “The Idea of Public Reason Revisited”. The University Chicago Law Review, 64, 3: 765-807.

(2001) Justice as Fairness. A Restatement. Edited by Erin Kelly. Cambridge: The Belknap Press of Harvard University Press. 
(2005) Political Liberalism. Expanded Edition. New York: Columbia University Press.

Silva, Ernesto (2013) Citado según:

http://www.eldinamo.cl/negocios/2013/05/08/diputados-rechazaron-veto-presidencial-parasituar-en-205-000-el-salario-minimo/

Tarud, Jorge (2013) citado según: http:/www.eldinamo.cl/pais/2013/06/16/diputadotarud-sobre-reajuste-al-salario-minimo-ofrecer-una-luca-mas-a-los-trabajadores-es-unaverdadera-burla/

Weber, Max (1988) „Politik als Beruf“, En: Max Weber, Gesammelte Politische Schriften Johannes Winckelmann (ed), Tübingen 1988, pp. 505-560.

Wolin, Sheldon (1992) "What Revolutionary Action Means Today". En Chantal Mouffe (ed.) Dimensions of Radical Democracy: Pluralism, Citizenship, Community. London/New York: Verso, pp. 240-253.

Žižek, Slavoj (2006) “Against the Populist Temptation”. Critical Inquiry 32 (Spring), pp. $551-574$. 